Jurnal Health Sains: p-ISSN: 2723-4339 e-ISSN: 2548-1398

Vol. 2, No. 4, April 2021

\title{
TINGKAT PENGETAHUAN PANDEMI COVID-19 KADER POSYANDU DI WILAYAH KERJA PUSKESMAS JAKARTA TIMUR
}

\section{Eka Rahmawati dan Tri Krianto}

Universitas Indonesia Depok, Jawa Barat, Indonesia

Email: ekkaa.rahma@gmail.com dan tjkarjoso@gmail.com

\begin{tabular}{l}
\hline ARTIKEL INFO \\
\hline Tanggal diterima: 5 April 2021 \\
Tanggal revisi: 15 April 2021 \\
Tanggal yang disetujui: 25 \\
April 2021 \\
\hline
\end{tabular}

\begin{abstract}
The COVID-19 pandemic is a challenge in efforts to improve Indonesia's health and development status. One of the impacts of this situation is the disruption in the implementation of health services in the community, such as the temporary closure or postponement of services at posyandu, which is a primary health service facility and is a major force in improving health status. The purpose of this study was to describe the level of COVID-19 pandemic knowledge of posyandu cadres at the East Jakarta. The research was conducted descriptively using a questionnaire. The research subjects were 382 posyandu cadres divided into 10 sub-district health centers in East Jakarta. The knowledge of posyandu cadres regarding the COVID-19 pandemic is generally good. However there are some questions with the lowest correct answers. 53.14\% of posyandu cadres do not know how to protect themselves from COVID-19 at home, $43.46 \%$ do not know body temperature which can be indicated as having contracted diseases including COVID-19, and $39.01 \%$ do not know the ethics of coughing /sneeze right.
\end{abstract}

Keywords:

knowledge level; COVID-19

pandemic; posyandu cadres.

\begin{abstract}
ABSTRAK
Pandemi COVID-19 ialah tantangan dalam upaya peningkatan derajat kesehatan serta pembangunan Indonesia. Salah satu akibat dari keadaan tersebut ialah terganggunya penerapan pelayanan kesehatan publik yaitu penutupan ataupun penundaan layanan di posyandu yang ialah sarana pelayanan kesehatan primer serta merupakan kekuatan utama dalam peningkatan derajat kesehatan. Tujuan penelitian ini untuk mengetahui gambaran tingkat pengetahuan kader posyandu terkait pandemi COVID-19 di Jakarta Timur. Penelitian dilakukan secara deskriptif menggunakan kuesioner. Subjek penelitian sebanyak 382 kader posyandu yang terbagi dalam 10 Wilayah Puskesmas Kecamatan di Jakarta Timur. Pengetahuan kader posyandu mengenai pandemi COVID-19 secara umum baik. Namun terdapat beberapa pertanyaan dengan jawaban benar terendah. Sebanyak $53,14 \%$ kader posyandu tidak
\end{abstract}

How to cite:

E-ISSN:

Published by:
Rahmawati Eka, et. al. (2021) Tingkat Pengetahuan Pandemi Covid-19 Kader Posyandu Di Wilayah Kerja Puskesmas Jakarta Timur. Jurnal Health Sains 2(4).

http://jurnal.healthsains.co.id/index.php/jhs/article/view/148

2723-6927

Ridwan Institute 
Kata Kunci:

tingkat pengetahuan;pandemi COVID-19; kader posyandu mengetahui bagaimana upaya untuk menjaga diri terhindar dari COVID-19 di rumah, 43,46\% tidak mengetahui suhu tubuh yang bisa diindikasikan sedang terjangkit penyakit termasuk COVID-19, dan 39,01\% tidak mengetahui etika batuk/bersin yang benar.

\section{Pendahuluan}

World Health Organization sudah mengkategorikan penyebaran Coronavirus Disease 2019 (COVID- 19) sebagai suatu pandemi global (Xu et al., 2020). Pemerintah sudah menetapkan keadaan tersebut sebagai musibah nasional lewat Keputusan Presiden Republik Indonesia No 12 Tahun 2020

(KemenKes, 2016). COVID- 19 awal dilaporkan di Indonesia bertepatan pada 2 Maret 2020 dengan jumlah kasus sebanyak 2 orang.

Tingkatan mortalitas COVID- 19 di Indonesia sebesar $8.9 \%$, angka ini ialah yang paling tinggi di Asia Tenggara (Susilo et al., 2020). DKI Jakarta merupakan provinsi dengan kasus tertinggi COVID-19 di Indonesia, terdapat 31.757 kasus terkonfirmasi pada 20 Agustus 2020 dengan angka positif terbesar terdapat di wilayah Jakarta Timur sebanyak 4.175 kasus (Rosidin \& Hamid, 2020).

Pandemi COVID-19 ialah tantangan dalam upaya peningkatan derajat kesehatan serta pembangunan Indonesia. Salah satu akibat dari keadaan tersebut ialah terganggunya penerapan pelayanan kesehatan publik yaitu penutupan ataupun penundaan layanan di posyandu yang ialah sarana pelayanan kesehatan primer serta merupakan kekuatan utama dalam peningkatan derajat kesehatan (UNICEF, 2011). Kader ialah ujung tombak dalam sosialisasi kepada warga. Kader kesehatan merupakan seorang yang diseleksi oleh warga serta bertugas untuk meningkatkan kesehatan warga dengan sukarela. Tugas kader salah satunya yaitu membagikan informasi kesehatan pada saat posyandu berlangsung (Pradana \& Casman, 2020).

$$
\text { Pendidikan kesehatan yang }
$$

disampaikan oleh kader posyandu berhubungan dengan masalah-masalah yang dialami masyarakat saat ini, sehingga bisa disimpulkan jika kader ialah sumber rujukan referensi masyarakat, dipercaya serta mempunyai ikatan yang dekat sebab kader ialah bagian dari masyarakat tersebut. Kedudukan kader dalam melaksanakan tugasnya selaku pemberi informasi kesehatan mempunyai pengaruh besar terhadap perilaku masyarakat (Pradana \& Casman, 2020). Pengetahuan ialah aspek penting yang dapat mempengaruhi perilaku kader. Pengetahuan sejalan dengan peningkatan perilaku kader dalam menyampaikan informasi kesehatan pada masyarakat (Eka et al., 2014). Bersumber pada pemaparan tersebut penulis bermaksud melaksanakan riset terkait tingkat pengetahuan kader posyandu pada pandemi COVID- 19.

\section{Metode Penelitian}

Jenis penelitian ini merupakan kuantitatif deskriptif dengan desain penelitian cross sectional yang bertujuan untuk mengetahui gambaran tingkat pengetahuan kader posyandu terkait pandemi COVID-19. Penelitian dilakukan di wilayah kerja Puskesmas Kecamatan yang berada di Jakarta Timur. Penelitian dilaksanakan pada bulan September hingga Desember 2020. Populasi dalam penelitian ini adalah seluruh kader posyandu di wilayah kerja puskesmas Jakarta Timur sebanyak 8.402 orang. Subjek penelitian sejumlah 382 di pilih secara acak dari masing-masing posyandu yang memenuhi kriteria inklusi yaitu merupakan kader posyandu aktif. Instrumen yang digunakan dalam penelitian ini adalah kuesioner yang terdiri dari 9 pertanyaan dan telah dilakukan uji validitas dan reliabilitas (Intan Pariwara, 2019). Daftar pertanyaan yang digunakan merupakan pertanyaan tertutup untuk 
memudahkan subjek penelitian dalam mengisi. Metode pengumpulan data dilakukan dengan cara mengisi googleform secara online. Semua data yang terkumpul kemudian dikaji ulang dan dilakukan proses pengolahan data dengan bantuan SPSS 20.

\section{Hasil dan Pembahasan}

\section{A. Hasil Penelitian}

Dari penelitian didapatkan hasil dan dimasukkan ke dalam klasifikasi tingkat pengetahuan kader posyandu terkait pandemi COVID-19 sebagai berikut:

\section{Tabel 1}

\begin{tabular}{ccc}
\multicolumn{3}{c}{ Karakteristik Responden Berdasarkan } \\
Umur \\
\hline $\begin{array}{c}\text { Karakteristik } \\
\text { Pendidikan }\end{array}$ & Frekuensi & Persentase \\
& &
\end{tabular}

\begin{tabular}{ccc}
\hline $23-35$ Tahun & 13 & 3,4 \\
\hline $36-45$ Tahun & 113 & 29,6 \\
\hline 46-55 Tahun & 183 & 47,9 \\
\hline$>55$ Tahun & 73 & 19,1 \\
\hline Total & 382 & 100 \\
\hline \multicolumn{3}{c}{ Tabel 2 } \\
Karakteristik Responden Berdasarkan \\
\\
$\begin{array}{cc}\text { Pekerjaan } \\
\text { Karakteristik } \\
\text { Pendidikan }\end{array}$ & Frekuensi & Persentase \\
\hline Tidak Bekerja & 365 & \\
\hline Bekerja & 17 & 95,5 \\
\hline Total & 382 & 100 \\
\hline
\end{tabular}

Tabel 3

Karakteristik Responden Berdasarkan Pendidikan

\begin{tabular}{ccc}
\hline $\begin{array}{c}\text { Karakteristik } \\
\text { Pendidikan }\end{array}$ & Frekuensi & Persentase \\
& &
\end{tabular}

\begin{tabular}{ccc}
\hline SD & 6 & 1,6 \\
\hline SMP & 45 & 11,8 \\
\hline SMA & 261 & 68,3 \\
\hline Diploma & 35 & 9,2 \\
\hline S1 & 32 & 8,4 \\
\hline S2 & 3 & 0,8 \\
\hline Total & 382 & 100 \\
\hline
\end{tabular}

Tabel 4

Klasifikasi Tingkat Pengetahuan Kader Posyandu Terkait Pandemi COVID-19 Tingkat

Pengetahuan

\begin{tabular}{|c|c|c|}
\hline Baik & 336 & 88 \\
\hline Cukup & 46 & 12 \\
\hline Kurang & 0 & 0 \\
\hline Total & 382 & 100 \\
\hline
\end{tabular}

Tabel 5

Tingkat Pengetahuan Kader Posyandu Terkait Pandemi COVID-19

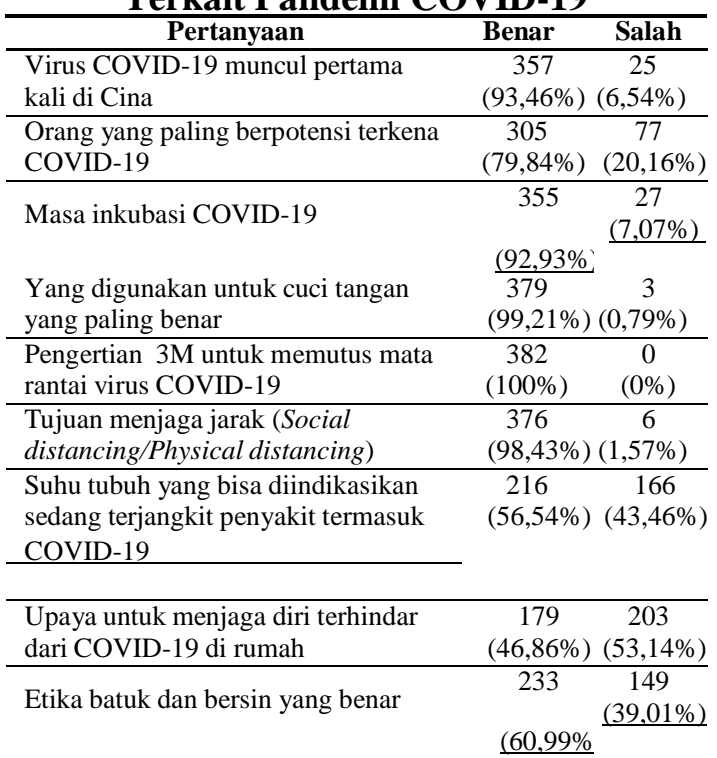

B. Pembahasan

Berdasarkan hasil penelitian menunjukkan bahwa karakteristik responden berdasarkan umur (Tabel 1) sebagian besar responden berumur 46-55 tahun, yaitu $183 \quad(47,9 \%)$ responden. Berdasarkan pendidikan (Tabel 2) bahwa sebagian besar responden dengan pendidikan terakhir SMA yaitu sebesar 261 $(68,3 \%)$ responden. Karakteristik responden berdasarkan pekerjaan (Tabel 3) menunjukkan bahwa sebagian besar responden tidak bekerja yaitu 365 (95,5\%) responden dan responden yang bekerja sebesar $17(4,5 \%)$ responden yang terdiri dari beberapa jenis pekerjaan seperti, wiraswasta, swasta dan juga guru.

Tabel 4 menunjukkan bahwa sebagian besar responden memiliki tingkat pengetahuan terkait pandemi COVID-19

Jurnal Health Sains, Vol 2, No 4, April 2021 
pada kategori baik, yaitu sebanyak 336 $(88 \%)$ responden. Namun, terdapat beberapa pertanyaan dengan jawaban benar terendah yang dapat dilihat pada Tabel 5 yaitu komponen pengetahuan terkait upaya untuk menjaga diri terhindar dari COVID19 di rumah sebesar 237 (62,04\%), suhu tubuh yang bisa diindikasikan sedang terjangkit penyakit termasuk COVID-19 sebesar $166(43,46 \%)$, etika batuk dan bersin yang benar sebesar $149(39,01 \%)$.

Hasil riset ini menggambarkan jika sebagian besar kader posyandu yang terdapat di Jakarta Timur memiliki pengetahuan yang baik tentang pandemi COVID- 19 sebesar 336 (88\%) responden. Pengetahuan kader posyandu bisa dipengaruhi oleh umur, pekerjaan, serta jenjang pendidikan kader, perihal tersebut sejalan dengan teori yang melaporkan jika pengetahuan ialah domain yang sangat berarti, tindakan yang dilakukan dengan bersumber pada pengetahuan akan bertahan lebih lama serta bisa menjadi perilaku yang akan selalu diterapkan oleh seorang dibanding bila tidak bersumber pada pengetahuan (Notoatmodjo, 2010).

Kader posyandu sebagai responden dalam riset ini didominasi oleh kader yang berusia dewasa yaitu 46- 55 tahun $(47,9 \%)$ serta pra lanjut usia yaitu 36- 45 tahun (29, $6 \%)$. Usia menunjukkan tingkatan kematangan seorang baik dalam berfikir ataupun dalam bertindak. Riset meyakinkan kalau usia bisa pengaruhi tingkatan pengetahuan serta keaktifan kader posyandu dalam melaksanakan tugasnya (Hapsari \& Veria, 2015).

Sebagian besar responden $(95,5 \%)$ tidak bekerja ataupun berperan selaku Ibu Rumah Tangga (IRT), sisanya $(4,5 \%)$ bekerja. Pekerjaan responden terdiri dari beberapa macam yaitu wiraswasta, swasta serta guru. Kader posyandu yang jadi responden dalam riset ini didominasi oleh Ibu Rumah Tangga (IRT) ataupun tidak mempunyai pekerjaan utama atau hanya mengurus keluarga. Hal tersebut sejalan dengan Panduan Kader Posyandu yang diterbitkan oleh Kemenkes RI yang mengharapkan kader mempunyai keahlian serta waktu luang dan bersedia bekerja secara sukarela. Banyaknya responden yang tidak bekerja dapat mempengaruhi responden agar lebih fokus dalam melaksanakan tugasnya selaku kader posyandu yang aktif (RI, 2014).

Kader posyandu dalam riset ini telah duduk di bangku pendidikan, dengan jenjang pendidikan terendah yang sempat ditempuh ialah Tamat Sekolah Dasar (SD) ataupun sederajat. Sebaran responden yang berpendidikan terakhir Sekolah Menengah Atas (SMA) ataupun sederajat mempunyai persentase terbanyak ialah 68,3\%, sebaliknya persentase terendah ada pada pendidikan terakhir Magister (S2) ialah $0,8 \%$ responden. Tingginya jenjang pendidikan umumnya akan diiringi dengan peningkatan pemahaman seseorang. Jenjang pendidikan kader posyandu berhubungan secara nyata terhadap pengetahuan (Chahyanto et al., 2019).

Pengetahuan merupakan hasil dari tahu, yang berlangsung sesudah orang melakukan penginderaan terhadap sebuah obyek tertentu (Kustantya \& Anwar, 2013). Penginderaan berlangsung melalui kelima indra manusia, namun sebagian besar melalui sebuah proses yakni proses belajar serta memerlukan sebuah dorongan, misalnya dorongan seorang yang lebih memahami sesuatu hal atau dorongan perlengkapan misalnya buku serta sebagainya (Notoatmodjo, 2010).

Pada riset ini, sebagian besar kader posyandu di Jakarta Timur memiliki pengetahuan yang baik tentang pandemi COVID- 19. Pengetahuan bisa berpengaruh terhada perilaku serta dapat mendorong kader posyandu agar melaksanakan suatu tindakan (Chahyanto et al., 2019). 
Tindakan tersebut seperti menyebarluaskan informasi mengenai cara pencegahan COVID-19 dan menghimbau warga masyarakat untuk mematuhi protokol kesehatan. Sehingga jika dilakukan pemberdayaan maka kader posyandu dapat diikutsertakan untuk membantu upaya pencegahan penyebaran COVID-19 khususnya di masyarakat dan dapat menggambarkan peran aktif kader posyandu di dalam upaya pencegahan dan penanggulangan pandemi di wilayah mereka (Nuriyanto, 2020).

\section{Kesimpulan}

Sebagian besar kader posyandu yang ada di Jakarta Timur mempunyai pengetahuan yang baik tentang pandemi COVID-19. Terdapat beberapa pertanyaan dengan persentase jawaban benar terendah yaitu terkait upaya untuk menjaga diri terhindar dari COVID-19 di rumah, suhu tubuh yang bisa diindikasikan sedang terjangkit penyakit termasuk COVID-19, dan etika batuk/bersin yang benar.

\section{BIBLIOGRAFI}

Chahyanto, B. A., Pandiangan, D., Aritonang, E. S., \& Laruska, M. (2019). Pemberian Informasi Dasar Posyandu Melalui Kegiatan Penyegaran Kader Dalam Meningkatkan Pengetahuan Kader Di Puskesmas Pelabuhan Sambas Kota Sibolga. Action: Aceh Nutrition Journal, 4(1), 7-14. Google Scholar

Eka, Y. C., Kristiawati, K., \& Rachmawati, P. D. (2014). The Factors That Influence Health Volunteers' Behavior In Early Detection Of Children Development Puskesmas Babat, Lamongan. Indonesian Journal of Community Health Nursing, 2(2), 57-66 Google Scholar

Hapsari, H. T., \& Veria, V. A. (2015). FaktorFaktor Yang Berhubungan Dengan
Keaktifan Kader Posyandu Di Wilayah Kerja Puskesmas Slawi Tahun 2015. Artikel Ilmiah. Google Scholar

Intan Pariwara, I. P. (2019). Faktor-Faktor Yang Berhubungan Dengan Partisipasi Ibu Balita Dalam Kegiatan Posyandu Di Wilayah Kerja Kelurahan 23 Ilir Palembang. Stik Bina Husada Palembang. Google Scholar

Kemenkes, R. I. (2016). Buku Kesehatan Ibu Dan Anak. In Kementrian Kesehat Ri Dan Jica Jakarta. Google Scholar

Kustantya, N., \& Anwar, M. S. (2013). Hubungan Tingkat Pengetahuan Dengan Perilaku Hidup Bersih Dan Sehat (Phbs) Pada Lansia. Jurnal Keperawatan, 4(1). Google Scholar

Notoatmodjo, S. (2010). Ilmu Perilaku Kesehatan. Penerbit Rineka Cipta. Google Scholar

Nuriyanto, A. (2020). Perkesmas: Aplikasi Keperawatan Profesional Di Puskesmas. Gmb-Indonesia. Google Scholar

Pradana, A. A., \& Casman, C. (2020). Pengaruh Kebijakan Social Distancing Pada Wabah Covid-19 Terhadap Kelompok Rentan Di Indonesia. Jurnal Kebijakan Kesehatan Indonesia: Jkki, 9(2), 61-67. Google Scholar

Ri, K. (2014). Pedoman Pelaksanaan Stimulasi, Deteksi Dan Intervensi Dini Tumbuh Kembang Anak Ditingkat Pelayanan Kesehatan Dasar. Jakarta2012. Google Scholar

Rosidin, A. B., \& Hamid, A. (2020). Media Online Dan Kerja Digital Public Relations Politik Pemerintah Provinsi Dki Jakarta. Wacana: Jurnal Ilmiah Ilmu Komunikasi, 19(2), 164-174. Google Scholar

Susilo, A., Rumende, C. M., Pitoyo, C. W., Santoso, W. D., Yulianti, M., Herikurniawan, H., Sinto, R., Singh, G., Nainggolan, L., Nelwan, E. J., Chen, L. 
K., Widhani, A., Wijaya, E., Wicaksana, B., Maksum, M., Annisa, F., Jasirwan, C. O. M., \& Yunihastuti, E. (2020). Coronavirus Disease 2019: Tinjauan Literatur Terkini. Jurnal Penyakit Dalam Indonesia. Google Scholar

Unicef, P. Des N. (2011). Fondo De Las Naciones Unidas Para La Infancia (Unicef). In Plan [Online]. Google Scholar

Xu, X.-W., Wu, X.-X., Jiang, X.-G., Xu, K.-J., Ying, L.-J., Ma, C.-L., Li, S.-B., Wang, H.-Y., Zhang, S., \& Gao, H.-N. (2020). Clinical Findings In A Group Of Patients Infected With The 2019 Novel Coronavirus (Sars-Cov-2) Outside Of Wuhan, China: Retrospective Case Series. Bmj, 368. Google Scholar

\section{Copyright holder:}

Eka Rahmawati dan Tri Krianto (2021)

First publication right:

Jurnal Health Sains

This article is licensed under:

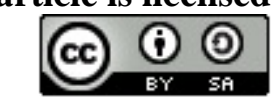

